\title{
SIDA en la ciudad de chihuahua: una realidad negada
}

alejandra lámbarri de legarreta

Escuela Nacional de Antropología e Historia, unidad Chihuahua

Al principio de la década de los ochenta hace acto de presencia un nuevo padecimiento que asombra al mundo médico primero y después a la sociedad: el VIH/Sida. Hoy el VIH/Sida ha cobrado dimensiones epidémicas, y aunque la epidemiología, la virología y la farmacéutica han logrado grandes avances, el flagelo ha cobrado más de trece millones de vidas en el mundo. En efecto, el $\mathrm{VIH} /$ Sida no es un padecimiento más; es, como ha escrito Susan Sontag, la madre de las metáforas sobre la enfermedad (Sontag, 1990).

Las ciencias sociales se han interesado desde hace tiempo por la forma en que cada grupo humano construye y vive la enfermedad; la sociología y la antropología médicas han realizado, entre otros, estudios sobre la relación médico paciente, la construcción social de la enfermedad, la diferencia entre enfermedad y padecimiento, o, como los estudios de Eduardo Menéndez (para mencionar un caso mexicano), sobre los sistemas médicos y la posición de poder que ocupa cada uno de ellos en nuestra sociedad (Menéndez, 1985). Anzures y Bolaños ha definido la antropología médica como "el estudio de los conceptos de salud y enfermedad, de causalidad nosológica y de terapéutica aplicadas en el marco de una determinada cultura, cualquiera que ésta sea" (Anzurez y Bolaños,1988:230), a lo cual debe añadirse el estudio de todo tipo de conflictos sociales que afecten al paciente. Ahora bien, en México, con algunas excepciones, como el trabajo del mismo Menéndez, tradicionalmente las investigaciones de antropología médica han centrado su atención en el mundo indígena, principalmente en lo que se ha dado en llamar medicina tradicional. En efecto, resulta claro que no es sino hasta hace relativamente pocos años que la antropología médica en este país comienza a ampliar su campo de interés más allá de la medicina tradicional, y da inicio una serie de investigaciones que vuelven sus ojos al que a falta de mejor término 
llamaremos el mundo occidental, que es, al fin y al cabo, el entorno en que se ha desarrollado la antropología como disciplina científica.

Es necesario señalar que desde un principio, el tema de nuestra investigación trataba menos sobre la concepción de la enfermedad en un medio urbano que sobre los efectos de la misma en la vida cotidiana de las personas. Nos parecían particularmente importantes el cáncer y el VIH/Sida. Nos inclinamos por este último por dos motivos principales, a saber: primero porque el estudio del VIH/Sida implica no sólo el de los efectos de la enfermedad propiamente dicha, sino también el de la discriminación y los prejuicios de que son objeto sus víctimas, y, en segundo, por la magnitud de la epidemia. Una vez escogido el tema de investigación, emprendimos la revisión bibliográfica. Durante ésta encontramos algunas investigaciones que trataban sobre el tema, pero ninguna, sin embargo, que se interesara por los problemas a los que se enfrentan las personas con $\mathrm{VIH}$ desde el punto de vista de los propios actores. Este vacío nos convenció de la necesidad de llevar a cabo una investigación como la que llevamos acabo. Consideramos que conocer el punto de vista de los propios actores acerca de sus dificultades y de las estrategias necesarias para resolverlas puede enseñarnos no sólo sobre las consecuencias físicas y sociales que implica un diagnóstico de seropositividad al $\mathrm{VIH}$, sino también sobre las condiciones sociales en que la epidemia se ha desarrollado en México.

En efecto, esta investigación se interesa por mostrar algunos de los rasgos que caracterizan la experiencia de un padecimiento como el VIH/Sida en un medio urbano, industrializado, del Norte de México; un medio, pues, vinculado irreversiblemente a un mundo global, y donde los avances médicos y los logros en materia de derecho impactan directamente a las personas que lo habitan. En función de este interés partimos principalmente de una interrogante: ¿cuáles son los problemas que las personas infectadas con VIH/Sida consideran más importantes y cuáles son las estrategias que emplean para 
enfrentarlos? Así pues, nuestro principal objetivo era registrar las dificultades percibidas como centrales por los propios afectados y, simultáneamente, dar cuenta de algunas de las estrategias adoptadas por los mismos para enfrentar las consecuencias de su nueva condición.

Muy bien. Teníamos ya preguntas formuladas y objetivos aclarados. Pero como todo buen lector de manuales de investigación sabe, faltaban las hipótesis, las benditas hipótesis. Y éstas, me susurraban al oído mis manuales, son mejores cuando parten de ciertos hechos más o menos sólidos. En el caso del VIH, el dato fundamental es que se encuentra rodeado de un conjunto de prejuicios y miedos, cuyo efecto más importante es que las personas infectadas sean objeto de discriminación. Pero ¿por qué? Una primera respuesta (un poco obvia, hay que reconocer) era que existe una relación muy estrecha entre la calidad y la cantidad de la información sobre el $\mathrm{VIH} /$ Sida y la persistencia de dichos prejuicios, y la posibilidad de que las personas infectadas enfrenten con éxito los mismos. Una segunda respuesta o hipótesis que parecía interesante poner a prueba era que entre las personas vinculadas con el VIH/Sida de forma directa (infectados) o indirecta (familiares, personal hospitalario) la información que circula sobre el VIH/Sida es o bien relativamente escasa o deficiente. En otras palabras, en un principio creíamos que: a) ciertos sectores de la población, sobre todo los infectados, sus familiares y muchos de quienes les atienden, carecen de la información correcta sobre los medios de transmisión, las manifestaciones clínicas y las consecuencias psicosociales del VIH/Sida; $y, b$ ), que la escasa información es uno de los principales causantes del rechazo social de que son objeto los infectados.

Si me permiten pasaré ahora a la metodología, un aspecto de la investigación que resulta un poco árido para casi toda la humanidad, con la excepción de antropólogos, sociólogos y demás seres extraños, para los cuales a veces es casi una obsesión. Esta investigación planteaba originalmente una 
aproximación a partir de lo que en ciertos textos se ha denominado narrativas de padecimiento ${ }^{1}$. A través de Fátima, una institución de beneficencia privada que trabaja con personas que viven con el VIH/Sida, se contactó a tres personas que dijeron estar dispuestas a participar en la investigación. Sin embargo, después de numerosas citas el resultado fue decepcionante: cuando llegaba la hora de la entrevista, acordada con anterioridad, ninguno acudía o incluso cuando nos citaban en sus domicilios no se encontraban. Pese a que comparto con la mayoría de los antropólogos la virtud de la terquedad, tras cinco meses de cancelaciones constantes parecía evidente la necesidad de un cambio en las estrategias de aproximación, e incluso en nuestra metodología. Por suerte, la Directora Ejecutiva de Fátima me informó -precisamente con motivo de una plática en donde se discutía la dificultad para que las personas accedieran a las entrevistas- sobre la única clínica de VIH en la ciudad. Esta clínica, que se lleva a cabo en el Hospital General de la ciudad de Chihuahua, "Dr. Salvador Zubirán", y tiene el larguísimo nombre oficial de Clínica del Paciente Inmunodeprimido del Servicio Especializado de Atención, o clínica del $\mathrm{VIH}$, como preferimos denominarla.

No sin cierto temor o, en honor a la verdad, completamente aterrados, acudimos al departamento académico de dicho Hospital para indagar si era factible la realización de trabajo de campo en la institución. Para nuestra sorpresa, el personal de la dirección académica se mostró interesado en el proyecto de tesis, aunque no tenían clara la finalidad de realizar una investigación antropológica en una institución de salud. Así pues, para evitar todo malentendido, fue necesario presentar un proyecto de investigación ante el comité de bioética de la institución, en el cual se exponía, de acuerdo con un formato de investigación de la Secretaría de Salud, las características y objetivos de la investigación.

\footnotetext{
${ }^{1}$ Las narrativas del padecimiento son similares a las "historias de vida del mal" (enfermedad), que, de acuerdo con ciertos autores, permiten llegar a una mejor comprensión del punto de vista del paciente y, por consiguiente, a una mejoría en la atención de los mismos (Brown, y Hatfield, 2000).
} 
Una vez aceptado el proyecto por el comité, se establecieron las posibilidades de acción dentro del hospital; por un lado acudiríamos todos los miércoles a la clínica de VIH en donde seríamos presentados a los pacientes por los médicos a cargo de dicha clínica; por otro, con una credencial del hospital tendríamos acceso a todas las instalaciones (incluyendo el piso en donde se ingresa a las personas con $\mathrm{VIH}$ ), al igual que a los pacientes en estado crítico o graves.

La clínica, que se lleva a cabo una vez a por semana, tiene como objetivo exclusivo atender a las personas que han recibido una prueba confirmatoria de la presencia del virus en su sangre. Es importante señalar que los médicos a cargo de la clínica realizan este trabajo por resolución propia. Todos comentaban, con frecuencia, lo difícil que era que médicos de distintas especialidades se sumaran al trabajo que realizan con personas infectadas con VIH.

A lo largo de cuatro meses nos dimos a las tareas favoritas de los antropólogos: observar, preguntar; asistimos a todas las consultas impartidas por la clínica que tuvieron lugar entre los meses de marzo y junio del 2002, que en total fueron 16. Presenciamos todas las consultas y registramos tanto los comentarios de los médicos a cargo como de los pacientes y familiares que acudían a consulta. Además de la observación participante, la técnica de acopio de información más importante fue la entrevista a profundidad no estructurada, casi ninguna de las cuales -con excepción de las realizadas fuera del hospital- pudo ser grabada en cinta magnetofónica.

Dado que la investigación se realizó en un espacio distinto al pensado al inicio, y a que la mayor parte de la investigación se llevó a cabo mediante la observación participante y las entrevistas en un espacio determinado, fue necesario adaptarnos a las condiciones que encontramos en la institución; por este motivo consideramos, aprovechando la nueva situación, que para 
comprender mejor los cambios y problemas era necesario entrevistar no sólo a las personas infectadas, como originalmente estaba planteado, sino también a los miembros de la familia con los que vive la persona. Es decir, ya iniciada la investigación comprendimos que registrar adecuadamente la experiencia de la persona con $\mathrm{VIH} /$ Sida implicaba registrar también cómo el virus afecta a las personas que conviven diariamente con ella.

Ahora bien, ¿cómo se desarrollaban las entrevistas? ¿Qué clase de información buscábamos y qué clase de información obteníamos? Ya la experiencia en Fátima nos había enseñado lo difícil que era obtener información sobre variables socioeconómicas básicas, como lugar de origen, ingreso, domicilio, nivel educativo, entre otras. En efecto, pese a tener claro desde un principio la clase de información que necesitábamos (y que valorábamos importante), muy pronto nos percatamos de que era prácticamente imposible dirigir el curso de las entrevistas, so pena de que los entrevistados dieran éstas por terminadas. Cierta clase de preguntas, posiblemente interpretadas por numerosos entrevistados como demasiado comprometedoras, a menudo condujeron a una serie de entrevistas truncas y de respuestas evasivas, en el mejor de los casos, o a la reticencia y silencio absoluto, en el peor. Ahora, si bien es de lamentarse esta falta de información, la reticencia, las evasivas y el silencio mostrados por estos primeros entrevistados son significativos por sí mismos, pues constituyen una muestra elocuente de esa estrategia que es simultáneamente una eficaz —quizá la única - forma de defensa individual de los infectados contra un mundo hostil y la causa de que sus intentos de organización colectiva hayan fracasado: el ocultamiento. 
Es posible identificar una serie de tópicos que aparecen una y otra vez a lo largo de casi todas las entrevistas: la discriminación, el rechazo, los problemas económicos, la desatención por parte del personal hospitalario, la falta de información, las enfermedades oportunistas y los efectos visibles del virus en el cuerpo, el desconocimiento de los derechos de las personas infectadas, el desgaste físico y emocional de las personas involucradas, y, no menos importante, el miedo y la angustia sobre el futuro. Como ya señalamos con anterioridad, todos estos temas fueron elegidos, si puede utilizarse ese verbo, por los propios entrevistados; nuestro papel consistió principalmente en tratar de que el entrevistado abundara sobre ciertos puntos. Si bien hubo informantes que aportaron mayor información que otros, no podemos considerar a ninguno como informante clave; la autocensura por parte de los propios entrevistados al sospechar que habían hablado de más, impidió con frecuencia un contacto más prolongado.

Cabe destacar, por último, los preceptos éticos que guiaron nuestra investigación: confidencialidad absoluta, consentimiento voluntario y exposición de riesgos. Es decir, a) aseguramos a los informantes que en ningún momento se presentarían testimonios que comprometieran su identidad; b) todas las entrevistas realizadas fueron realizadas con permiso expreso del entrevistado, y c) se expuso de manera clara a los entrevistados los riesgos de aceptar participar en la investigación, se aclararon las dudas de las personas entrevistadas sobre la finalidad de la investigación, y, en ocasiones, los motivos del investigador para abordar el tema en cuestión. 
${ }^{2}$ Para mayor información ver Berkow (dir. Ed.) El manual Merck de diagnóstico y terapéutica, Océano/Centrum, Barcelona, 1992 pp 197-206, 307-333, 334-351, 2417-2425.

${ }^{3}$ Organización de las Naciones Unidas, 2001, Asamblea General, Informa del Secretario General, "Esxamen del virus de la inmunodeficiencia humana/sindrome de inmunodeficiencia adquirida en todos sus aspectos" 
Por último, en el cuarto capítulo exponemos partes de nuestro material empírico. Las entrevistas fueron organizadas en función no de los entrevistados, sino de los problemas y de las estrategias identificados por los propios actores. Debido a que resultaba un poco complicado darle nombre a los problemas, consideramos que resultaría ilustrativo elegir frases de los propios entrevistados que ejemplificaran de manera más personal la problemática expresada en los argumentos. Primero aparecen los problemas, los cuales ordenamos de acuerdo con el grado de importancia otorgado a los mismos por los propios entrevistados o, mejor dicho, en función de la importancia percibida por los afectados: exponemos primero los problemas que la mayor parte de los entrevistados considera más graves y difíciles de enfrentar y/o solucionar. Los problemas constituyen subapartados, los cuales están estructurados de la siguiente manera: cada uno comienza con una breve introducción, que contiene información general relativa al problema y extractos de entrevistas; posteriormente se presenta un breve perfil del informante, en el cual se intercalan extractos de las entrevistas, datos, citas, cifras y análisis de otros investigadores. La finalidad de esta organización es vincular la percepción que los informantes poseen sobre los problemas con la imagen que arroja cierta clase de información más "objetiva". 
De acuerdo con nuestras hipótesis principales, la información -mejor dicho, su distribución desigual entre los distintos sectores sociales- desempeña un papel central en la forma como las personas se relacionan con el VIH/Sida. Desde luego, la idea no es ni nueva ni desconocida, de hecho, es una opinión habitual afirmar que el acceso a la información es la clave para frenar la expansión de la epidemia. ¿Hasta que punto esto es cierto? En la medida en que lo permiten los límites empíricos y teóricos de este trabajo, la respuesta a la anterior pregunta sería no. En efecto, al menos en el caso del VIH/Sida, la información es el sine qua non de cualquier intento por combatir la epidemia, es un ingrediente esencial, indispensable, pero no suficiente. $\mathrm{Y}$ no lo es porque existen fenómenos sociales e históricos que por decirlo de cierta forma, debilitan la influencia de la información sobre el VIH/Sida. Pensamos, sobre todo en dos: uno es la persistencia del patriarcado como una "estructura básica" de nuestras sociedades (Castells:2000) y, el otro, una tendencia estructural a la negación de la enfermedad ${ }^{5}$. Ambos representan, a nuestro juicio, límites difíciles de franquear a, digamos, las campañas que buscan convencer a la población de la necesidad de utilizar el condón o que luchen contra la discriminación de las personas con VIH/Sida. Por ejemplo, aunque poseen la información necesaria, numerosas mujeres no están en la posición de demandar el uso del condón a su(s) pareja(s) sexual(es) debido a en términos generales ocupa una posición social inferior. La discriminación y el

\footnotetext{
4، una estructura básica de todas las sociedades contemporáneas. Se caracteriza por la autoridad, impuesta desde las instituciones, de los hombres sobre las mujeres y sus hijos en la unidad familiar. Para que ejerza esta autoridad, el patriarcado debe dominar toda la organización de la sociedad, de la producción y el consumo a la política, el derecho y la cultura. Las relaciones interpersonales y, por lo tanto, la personalidad están también marcadas por la dominación y la violencia que se originan en la cultura y las instituciones del patriarcado" (2001:159-160).

${ }^{5}$ Giddens propone el concepto de secuestro de la experiencia para aludir al hecho de que en la modernidad tiene lugar una "separación de la vida cotidiana del contacto con experiencias que plantean cuestiones existenciales potencialmente perturbadoras (en especial, experiencias relacionadas con la enfermedad, la locura, la criminalidad, la sexualidad y la muerte)"(2000:295). Existen cinco ámbitos en los que se presentan procesos de secuestro institucional en el sentido de "la acumulación de procesos que hacen eficazmente extrínsecas ciertas influencias difíciles de sobrellevar", los cuales "tienen el efecto de suprimir ciertos aspectos básicos de la experiencia de la vida, sobre todo las crisis morales, de las regularidades de la vida cotidiana instituidas por el sistema abstracto de la modernidad"(2000:195). Estos ámbitos son: la locura, la criminalidad, la enfermedad y la muerte, la sexualidad y la naturaleza.
} 
rechazo a personas infectadas por su lado, si bien en ocasiones responde a la falta de información, con mucha frecuencia parecen estar más bien motivadas por su asociación a la homosexualidad, como es el caso de México. Y la homofobia no es sino producto del intento a menudo violento por imponer a todos la heterosexualidad obligatoria, elemento básico del patriarcado. Por fortuna, ni el patriarcado ni la negación estructural de la enfermedad constituyen realidades homogéneas o libres de contradicciones: ambas pueden (y deben) ser cuestionadas, como de hecho está ocurriendo.

El VIH/Sida es en cierto sentido un fenómeno paradójico, pues al tiempo que representa una de las expresiones más claras de las consecuencias del "secuestro" institucional de la enfermedad, constituye hoy día una de las armas más eficaces para combatirlo. En otros términos, si bien la magnitud de la epidemia del $\mathrm{VIH} /$ Sida ha evidenciado de manera contundente la dimensión de la represión institucional de la enfermedad (ha puesto de manifiesto, como muy pocos fenómenos lo han hecho, los innumerables mecanismos de esta maquinaria de la exclusión), también nos ha obligado a discutir públicamente sobre enfermedad, sexualidad y muerte. De ahí se sigue que quizá el VIH/Sida representa, inesperadamente, hoy por hoy uno de los fenómenos que más profundamente socavan esta negación estructural de la enfermedad al volverla visible, al "desvelarla". Está en nuestras manos aprovecharlo y reforzarlo mediante el debate público, políticas de salud efectivas y programas de prevención.

Ahora bien, ¿cuáles son algunos de los problemas que afectan a las personas infectadas con el VIH y de que manera los enfrentan? Podemos decir que destacan el rechazo y la discriminación; la "homosexualización" del Sida y por lo tanto las personas infectadas con el virus del VIH (fenómeno que es un problema sólo en tanto, por desgracia, vivimos en una sociedad donde la homofobia es moneda corriente); la dificultad para aceptar su nueva condición y las consecuencias que de ello se derivan: el retraso del inicio del tratamiento 
y la negativa a tomar medidas de protección y los grandes vacíos en materia de derecho de las personas que viven con el VIH; los elevados costos de los medicamentos $\mathrm{y}$, de gran importancia, una desinformación crónica con respecto a los distintos aspectos (médicos y sociales sobre todo) de la epidemia. De la misma manera encontramos que las personas recurrían a una serie de estrategias similares para hacer frente a estos problemas, la más importante de las cuáles es el silencio; es decir el ocultamiento de su condición de seropositividad al mayor número de personas posible, y lo que en este trabajo decidimos denominar la "confesión selectiva", estrategia que consiste en comunicar su condición sólo a un número de personas.

Si bien el lector tiene la última palabra sobre el mérito de este trabajo, consideramos que puede contribuir a desarrollar programas de atención y prevención del VIH/Sida más sensibles y adecuados a las necesidades "reales" -en tanto percibidas- de los destinatarios de dichos programas. Para bien o 
para mal, los programas de salud en sociedades tan diversas y complejas como la nuestra deben buscar un equilibrio entre lo particular y lo general, es decir, tienen que buscar atender con eficacia a personas muy distintas entre sí que a menudo sólo tienen en común sus dificultades. Es cierto que las personas ahora denominadas PVVIH (personas que viven con el $\mathrm{VIH}$ ) experimentan numerosos problemas que dependen en primer lugar de condiciones sociales específicas, y es de vital importancia que se lleven a cabo investigaciones que den cuenta de manera detallada del papel que juegan dichas condiciones en el curso de la enfermedad o padecimiento; es también indispensable, sin embargo, conocer mejor aquellos problemas y estrategias que se presentan con relativa independencia de clase, género, edad, u origen étnico. Vistas desde esta perspectiva, las contribuciones de estos dos tipos de investigaciones son complementarias, no se excluyen mutuamente.

\section{BIBLIOGRAFÍA}

ANZUREZ y Bolaños, María del Carmen, (1988) "La medicina tradicional, en La antropología en México. Apnorama Histórico. 4. Las cuestiones medulares.(Etnología y antropología social. Martín Villalobos (coord), INAH, México D.F.. pp. 227-260

BOTINAS, Lluís, (1997) "EI VIH no existe", en www.free-news.org BOURDIEU, Pierre, (1990) Sociología y Cultura, Grijalbo/Conaculta, México D.F.

BROWN, J. Peter y Kendra Hatfield Timajchy, (2000)“Padecimiento", en Diccionario de Antropología, Thomas Barfield, (ed) Siglo XXI, México D.F., pp 389-390.

CASTELLS, Manuel, (2001), La era de la información. Economía, sociedad y cultura. El poder de la identidad. Vol II. Siglo XXI, México D.F.

GIDDENS, Anthony, (2000), Modernidad e Identidad del yo. El yo y la sociedad en la época contemporánea. Península, Barcelona, España.

GOFFMAN, Erving, (1993), Estigma. La identidad deteriorada. Amorrortu, Buenos Aires, Argentina. 
GRMEK, Mirko, (1992) Historia del sida, Siglo XXI, México, D.F.

KÜBLER-ROSS, Elizabeth, (1975) Sobre la muerte y los moribundos. Grijalbo/Mondadori, Barcelona, España.

LIZARRAGA, Xavier, (1991) "Circuitos afectivos del Sida" en Salud Problema, Nueva Epoca, Año 3, número 4, junio, UAM-Xochimilco, México, D.F., pp71-82. MENENDEZ, Eduardo, (1985) "Modelo Médico Hegemónico, Modelo alternativo subordinado, Modelo de autoatención. Caracteres estructurales", en Cuadernos de la casa Chata, número 86, México D.F.

Organización de las Naciones Unidas, (2001) Asamblea General Exámen del virus de la inmunodeficiencia humana/síndrome de inmjnodeficiencia adquirida en todos sus aspectos., Informe del Secretario General.

SONTAG, Susan, IIIness as a Methaphor and Aids and its methapors, Anchor Books, New York, USA. 